\title{
Workshop report
}

\section{Third Eastern European Workshop on Diabetes Education of the Diabetes Education Study Group}

\author{
Held in Warsaw, Poland in September 1987
}

\author{
V.Jörgens and P. Kronsbein \\ Department of Metabolic Diseases and Nutrition, University of Düsseldorf, \\ WHO Collaborating Center, Düsseldorf, Federal Republic of Germany
}

According to a 1981 decision of the Diabetes Education Study Group (DESG) of the European Association for the Study of Diabetes, specific symposia on diabetes education should be implemented for Eastern European diabetologists and their health care teams. It was decided to organise these symposia along similar lines as the 4-day workshops already being performed with great success and "tradition" in Geneva under the leadership of Dr. J.P.Assal.

The first Eastern European Workshop on Diabetes Education of the DESG took place in Bucharest, Rumania in 1982 with Professor I. Mincu and co-workers as the hosts and local organisers. Approximately 35 colleagues from six Eastern European countries participated at this symposium. There was general consensus that this meeting had been most successful in stimulating the initiative to set up centres for diabetes education in various countries, and to foster bi- and multilateral cooperative efforts concerning the improvement of clinical practice and research in diabetes care.

The activities of this initial meeting resulted in the demand for and necessity of a second Eastern European Workshop on Diabetes Education which subsequently took place in Balatonfüred, Hungary, from 6-9 October 1985 with Drs. J. Fövenyi (Budapest) and K. Simon (Szekesfehervar) as hosts and local organisers. Official delegations from 7 Eastern European nations attended, with a total of approximately 70 participants.

Once again, the discussions and results of this workshop were very fruitful. At this time the participants saw the need for a bi-annual meeting to encourage further progress in diabetes education and care in Eastern Europe.

The third Eastern European Workshop took place in Warsaw, Poland from 10-13 September 1987.

Like the first two workshops this symposium was organised on behalf of the DESG by Drs. M. Berger and V.Jörgens (Düsseldorf, FRG) with the helpful support from WHO, Division of Non-Communicable Diseases. Professor J. Taton and his team organised the workshop locally and warmly welcomed the participants.

Official delegations from Bulgaria, Czechoslovakia, German Democratic Republic, Hungary, Poland, Rumania, and the Soviet Union comprised the group of approximately 70 participants. In addition the VicePresident of the DESG Dr. J.Day (Ipswich, UK), and Dr. H. King from the WHO Division for Non-Communicable Diseases/Diabetes (Geneva, Switzerland) were most active participants of the meeting. More than half of the colleagues present were already acquainted with each other from the two preceding workshops.

The first day of the workshop was dedicated to presentations by the various participating diabetes centres. Nearly 50 different centres engaged in the education and care of diabetic patients displayed their activities. The participants were informed in detail about local facilities and specific methods of patient education as well as about specific strengths and problems of diabetes education and care in the different centres. In comparison to the information which was presented two years ago in Hungary and 5 years ago in Rumania, nearly all the centres reported gradual improvement in their treatment and education programmes. All participants agreed that education has to be an integral part of therapy. Only a well-informed patient is able to participate successfully in his own therapy so that he can handle such daily necessities as metabolic self-monitoring, adaptation of the insulin dose to specific circumstances of life, selection of proper food, and appropriate foot care. For Type 1 (insulin-dependent) diabetic patients the beneficial effects of a structured diabetes teaching and treatment programme were presented; as a direct result of the first workshop in $\mathrm{Ru}$ mania a cooperative study of a 5-day inpatient diabetes teaching and treatment programme (DTTP) was introduced and evaluated in a Bucharest hospital (Bucharest-Düsseldorf study). This study demonstrated the efficacy of an intensive DTTP based upon group 
teaching techniques and the availability of modern metabolic self-monitoring materials in improving the long-term quality of diabetes care (Mühlhauser et al. (1987), Diabetologia 30: 681-690).

During the second day of the meeting the participants discussed self-selected topics of diabetes treatment in three parallel workshops of not more than 15 members with intensive discussions and group interaction. The following topics were selected by the participants for discussions during that day: Intensified Insulin Therapy, Diet for Type 1 Diabetes, Pregnancy and Diabetes, Child Care, Type 2 (non-insulin dependent) Diabetes, Therapeutic Goals, Teaching Methods, Evaluation, Social Problems, and Patient Organisations. The working process and the results from each group were visualised on large charts. During the third and last day of the meeting, the results from various group sessions were presented to, and discussed by, the plenary.

As reflected by its selection as a major topic of a working party "Patient Organisations" was considered very important. At the moment, only Poland has an association for (and of) diabetic patients. This association organises activities all over the country, including information meetings for patients and the publication of patient booklets. The Polish Diabetic Association and its President who participated at the workshop were congratulated for their beneficial activities; and strongly encouraged to continue their efforts, which provide a model for other Eastern European countries.

With respect to modern materials for the treatment of diabetes mellitus, in the last few years some Eastern European countries have been manufacturing their own products of moderate to good quality. Especially the production of good quality strips for blood glucose self-monitoring should be increased; and these materials should be available not only in East Germany as the producer, but also be exported to other socialist countries. Besides these vital self-monitoring materials, there are developments in the area of sophisticated insulin-application materials: In Czechoslovakia the "Madi-pen" is being produced, which has been called the "most democratic insulin pen in the world", because it can be filled - in contrast to Western products - with any insulin available.

Towards the end of the meeting, the participants expressed great satisfaction with the results of the meeting; and confirmed the necessity for continuation of these workshops to foster the concept of patient treatment and patient education being a unity. According to a general consensus Dr. J. Fövenyi (Budapest) was elected Chairman of the Eastern European Group of the DESG (succeeding Prof. Mincu who retired by rotation), Professor Taton (Warsaw) was elected ViceChairman, and Dr. Wenzel (Bad Berka, GDR) Secretary for the next 2 years. Finally, it was decided that the fourth Eastern European Workshop on Diabetes Education of the DESG will be held in Weimar, GDR, in 1989 locally organised by Dr. Wenzel and co-workers.

Dr. V.Jörgens and P. Kronsbein

Department of Metabolic Diseases and Nutrition University of Düsseldorf WHO Collaborating Center Moorenstr. 5

D-4000 Düsseldorf 1

FRG 